\title{
The Use of External Support in the Treatment of Low Back Pain
}

\author{
JACQUELIN PERRY. M.D. ${ }^{1}$
}

$1 \mathrm{HE}$ origin of therapeutic procedures can generally be traced to local efforts directed toward resolving continuing disability of the patient. In the treatment of low back pain, this approach often included designing special supports by individual physicians and orthotists. Such independent activity in numerous locales resulted in a long list of brace designs, many of which carry impressive eponyms that tend to stress differences rather than elements of commonality.

To compile the available information concerning bracing, the American Academy of Orthopaedic Surgeons published the Orthopaedic Appliances Atlas (1) in 1953. Of the 30 types of spinal support described in that volume, 17 were specifically designed for the sacroiliac or lumbosacral areas. Ten years later, in 1962, a survey of orthopedic services in the United States by Nattress and Litt (2) identified 30 braces, of which 22 corresponded to the design customarily considered effective at the lumbosacral region. These two reports, along with the present study, described a total of 40 different devices designed for low back problems.

Details of designs are readily available, but objective criteria to weigh the relative merits of the different devices are almost nonexistent. As a consequence, physicians generally make their selection either by adopting the customs observed during their training, or by accepting the preference of the local orthotist. Undoubtedly, some braces have withstood

' Chief, Kinesiology Service, Rancho Los Amigos Hospital, Downey, Calif.; Associate Clinical Professor of Orthopaedic Surgery, University of Southern California School of Medicine, Los Angeles. the test of time, while others have become items only of historical interest. Superimposed on this background, the more recent introduction of prefabricated parts for brace construction has probably influenced the frequency with which certain types of braces are prescribed.

The extent to which these influences have altered the availability and prescription of brace designs today has not been reported. Also unknown is the nature of the relationship between the etiology of the low back pain and the type of support that clinicians have found to be effective. Identification of this type of information is pertinent because the subject of orthotics is now being presented in formally organized courses on a nationwide basis.

This paper records the results of a three-phase study conducted in 1968-69 by the Subcommittee on Orthotics, Committee on Prosthetic-Orthotic Education (CPOE) of the National Research Council. Approval of the Executive Committee of the American Academy of Orthopaedic Surgeons was obtained. The purpose of the survey was to identify the current practices of orthopedic surgeons with respect to external supports for the management of low back pain.

\section{METHOD}

\section{PILOT STUDY}

An unstructured pilot questionnaire was sent to 150 orthopedic surgeons selected because of their considerable experience in the management of low back pain. They were asked to list the types of support they prescribed, and to indicate the clinical conditions for which each support 
was chosen. The results of this pilot study formed the basis for the next phase of the investigation.

The 90 physicians $(60 \%)$ who responded were explicit in their choice of a device and the clinical indication for its use. Eighty-three reported frequent prescription of external support as part of their therapeutic program. (Two said they never used external supports, and five indicated they rarely prescribed such aids.)

Within each class of support (brace, corset, cast), a similar pattern of practice was evident. Numerous designs were listed, but most were mentioned only occasionally. The majority of the respondents preferred one or two types of support. Within a total of 12 different braces reported, three-fourths of the physicians listed the Chairback (Knight) and Williams braces (Figs. 1, 2, and 3). Six other designs were mentioned only once. Identification of corset preference was a bit clouded by the indiscriminate use of both generic and trade names. The generic term "lumbosacral" was specified by half of those responding. An additional onefourth of the pilot-study participants used trade names such as Camp, Spencer, and Winchester. The next most frequently mentioned device was the sacroiliac belt $(8 \%)$. Of the six casts identified, the flexion jacket was preferred by more than half of the pilot-study orthopedists; the second choice was the body jacket (19\%).

In designating the clinical conditions warranting external support, two response patterns developed in the pilot survey. Seven types of disability were mentioned frequently and in explicit terms, viz., postoperative fusion, spondylolisthesis, chronic backache, acute strain, disc syndrome, degenerative joint disease, and the postoperative disc. Several other conditions, identified by a wide variety of terminology, were mentioned with moderate to rare frequency.

\section{NATIONAL SURVEY OF AAOS}

The findings of the pilot survey were used to construct a questionnaire applicable for a comprehensive national study. This questionnaire was sent to the membership of the American Academy of Orthopaedic Surgeons (AAOS). The form (presented at the end of this article) was a check sheet on which physicians were asked to match the types of support they prescribed with the clinical conditions they treated in this manner.
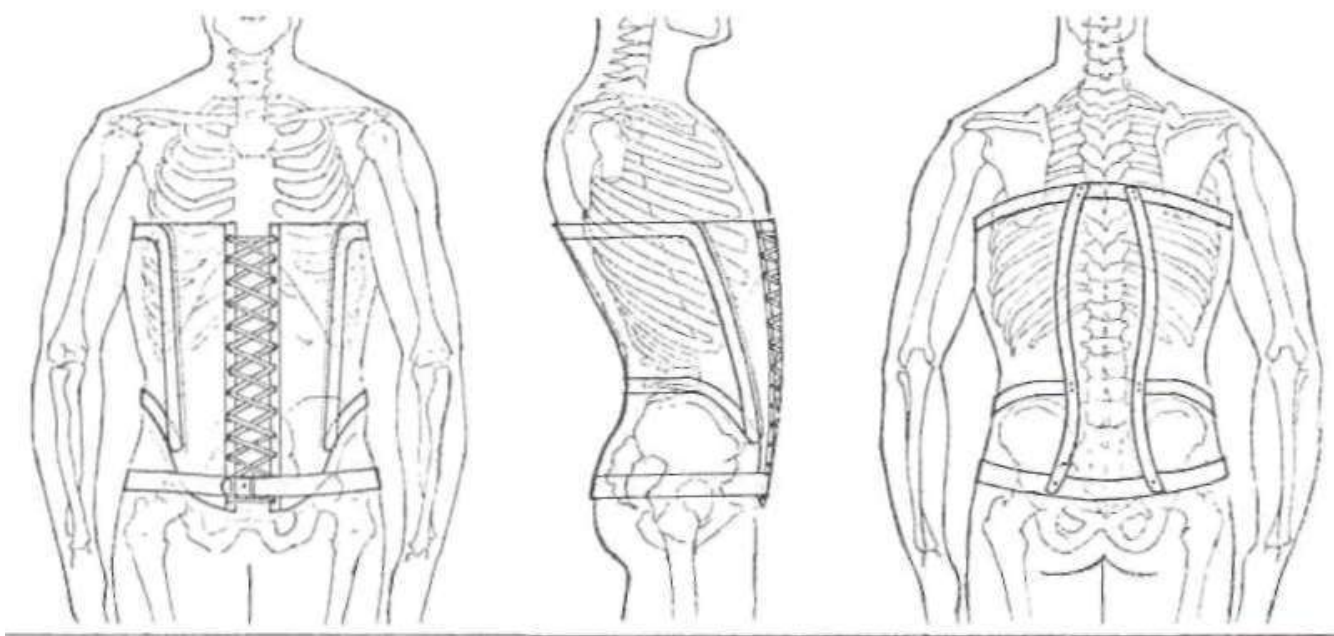

Fig. 1. The Knight dorsolumbar brace. 

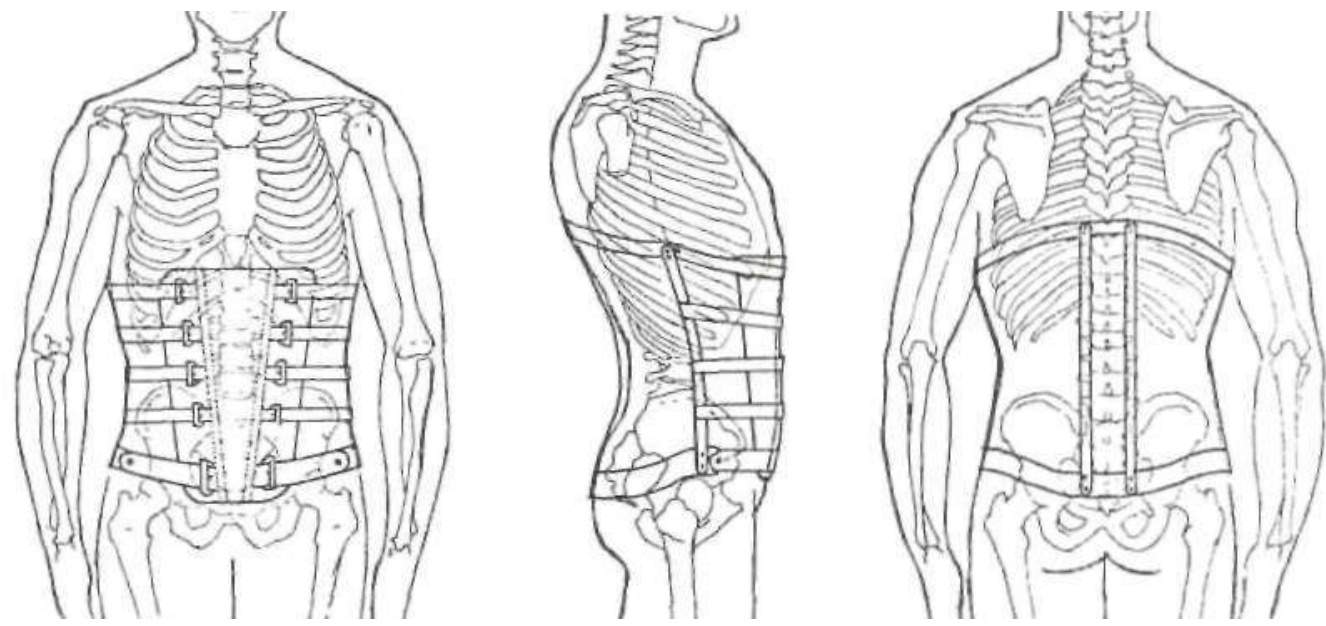

Fig. 2. A typical modification of the Knight brace.
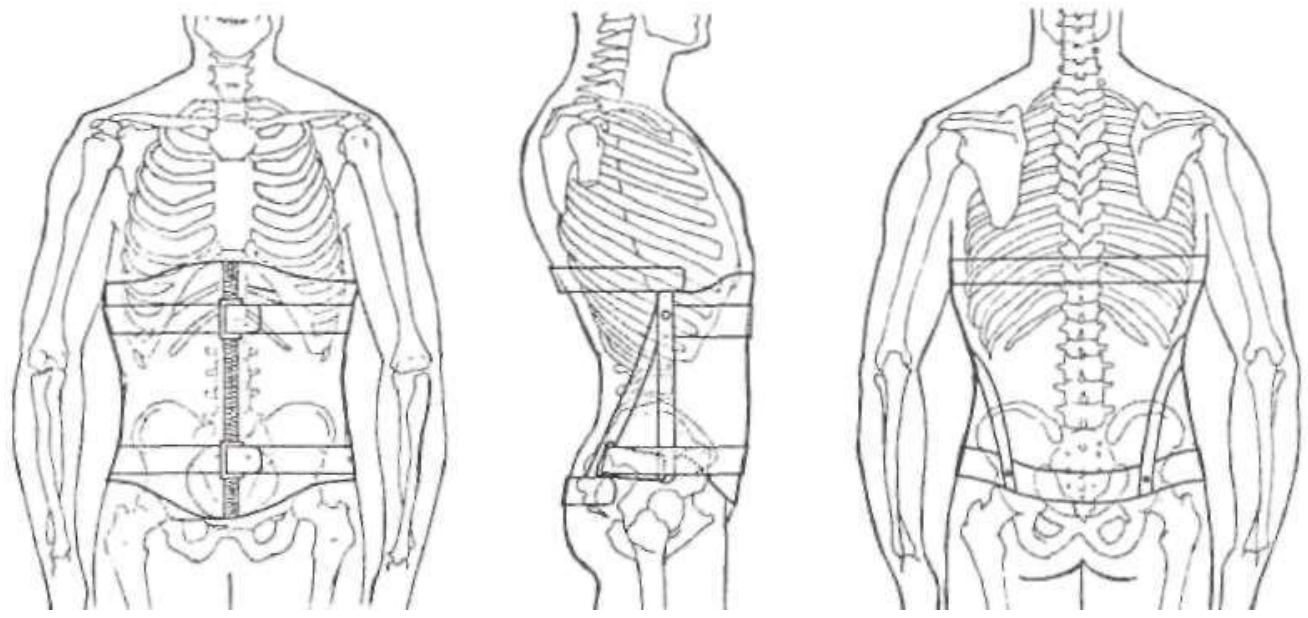

Fig. 3. The Williams lumbosacral brace. (Illustrations from Orthotics for Physicians and Therapists, Prosthetic-Orthotic Education, Northwestern University Medical School, Chicago, HI.)

The following supports, all of which were more than rarely mentioned in the pilot study, were included. (The restriction on corset choice was the result of a decision to use generic rather than trade names in order to avoid repeating the confusion produced in the pilot study.)

\section{Braces}

1. Chairback (Knight)

2. Williams

3. Norton-Brown
4. Goldthwaite

5. Bennett

Corsets

1. Lumbosacral

2. Sacroiliac

Casts

1. Flexion

2. Body jacket

3. Cast with one leg

Eleven clinical conditions were selected for the national inquiry, based upon the 
returns of the pilot study and upon the clinical experience of the NRC committee. Provision was made throughout for physicians to indicate devices or clinical problems other than those listed on the form. The questionnaire was also designed to indicate the relative frequency ("usually" or "rarely") of the prescriptions.

\section{SURVEY OF THE FUNCTIONS OF SUPPORT}

Late in 1968, a second national survey was conducted among the AAOS membership to determine prevailing opinions about the functions of the various types of support. The purpose of this phase of the study was to attempt to relate the anticipated function of the external support to the different preferences in prescription.

Profiting from the findings of part one of the national survey, the list of supports was again shortened. This time, the orthopedists were queried about two braces (Williams and Chairback [Knight]); "corset" was listed as a single category, as were the flexion casts. A miscellaneous category was added for other comments. (The questionnaire appears on page 57.)

Six probable functions were selected for study. These included: immobilization of the spine, restriction of lumbosacral motion, unloading of the intervertebral disc, support of the abdomen, correction of posture, and psychological effect. As always, there was a provision for other choices.

\section{RESULTS}

On the first national survey, 5,215 questionnaires were mailed. With the aid of one follow-up, 3,140 (60\%) were returned completed. An additional $1 \%$ of the returns were incomplete because the physicians had retired or their practices did not include patients with low-back problems.

In the second phase of the study, the same number of forms were sent out, with $2,192(42 \%)$ being filled in and returned. No follow-up mailing was conducted,

Annotated responses or explanatory letters accompanied $1,034(33 \%)$ of the questionnaires. These consisted of: (a) identification of the type of device they preferred if it was not specifically mentioned on the form; (b) comments regarding precise fitting or construction characteristics considered to be important; (c) reasons for not prescribing external support; and $(d)$ other modes of treatment which should accompany use of a support.

\section{USE OF SUPPORTS FOR LOW-BACK PROBLEMS}

Most of the orthopedic surgeons indicated use of a judicious selection of braces, casts, and corsets; the average physician reported that he used three different devices in his practice. A small group stated that they used only one type of device: a brace (4\%), a corset (4\%), or a cast $(1 \%)$. Only 14 respondents stated that they "never used support" for the patient with a low-back problem.

Among the clinical indications, the inclusion of the term "fracture" caused considerable confusion in the information collected. Either all types of braces are used for fractures in the "low back," or the orthopedist's attention was directed to fractures of the spine in general. The latter seemed highly probable, as most indicated that a brace other than those listed was used. Typically, these were the Jewett, Taylor, and Baker types, commonly used for lesions in the thoracic and thoracolumbar areas. As the extent of this confusion could not be identified, all data referring to "fracture" were omitted from the analysis.

Certain characteristics in the prescription of external support became evident. A majority of the profession used the same groups of devices. The nature of the disability dictated the frequency of prescription as well as the type of support preferred.

\section{SUPPORT PREFERENCE}

The lumbosacral corset is the most popularly used low-back support, followed by the Chairback (Knight) spinal brace. Utilization of the other types of 
support fell far behind these two leaders (Table 1).

The degree of dominance by the lumbosacral corset varied with the method of comparison; $28.5 \%$ of the physicians indicated use of the lumbosacral corset for at least one condition. When all clinical indications were considered, preference for the lumbosacral corset was $44.2 \%$. The Chairback brace was used by $21 \%$ of the physicians for $22 \%$ of the clinical conditions listed. All other types of support were used less than $9 \%$ of the time. The Williams brace was third in popularity. A variety of casts preceded any other choice of brace or corset (Table 1).

As "lumbosacral corset" is a generic term that overlooks design differences between the Camp, Winchester, Spencer, and other specific corset styles, a comparison was made with the designated preferences for the total group of "low-back braces." The relative preference between the corset and the low-back brace again depended on the method of comparison. The use of a brace at some time was indicated by $40.2 \%$ of the physicians, in comparison to $32.4 \%$ for corsets. However, when all the clinical indications were totaled, the preference reversed, with the corsets dominating $(46.7 \%$ in contrast to $39.0 \%$ for braces).

Some geographic patterns for brace preference were found, especially for

Table 1. Support Prefrerence

\begin{tabular}{lcr}
\hline \multicolumn{1}{c}{ Support } & $\begin{array}{c}\text { By Individual } \\
\text { Physician } \\
\text { (\% Response) }\end{array}$ & $\begin{array}{c}\text { For Al Clinical } \\
\text { Indications (\%) }\end{array}$ \\
\hline Lumbosacral corset & 28.5 & 44.2 \\
Chairback (Knight) brace & 21.1 & 22.4 \\
Williams brace & 9.9 & 8.3 \\
Body cast & 9.2 & 6.3 \\
Flexion cast & 8.4 & 5.0 \\
Body cast + 1 leg & 6.0 & 2.6 \\
"Other" braces & 5.6 & 3.7 \\
Goldthwaite brace & 2.4 & 1.4 \\
"Other" corsets & 2.3 & 1.3 \\
Bennett brace & 2.1 & 1.9 \\
Norton-Brown brace & 1.5 & 1.3 \\
Sacroiliac corset & 1.6 & 1.2 \\
"Other" casts & 1.2 & 0.5 \\
\hline
\end{tabular}

Table 2. Support Prefrerence by States

\begin{tabular}{lccc}
\hline \multirow{2}{*}{\multicolumn{1}{c}{ Support }} & \multicolumn{3}{c}{$\begin{array}{c}\text { Number of States with this } \\
\text { Level of Preference }\end{array}$} \\
\cline { 2 - 4 } & First & Second & Third \\
\hline Lumbosacral corset & $43.5^{\mathrm{a}}$ & $5.5^{\circ}$ & 1 \\
Chairback (Knight) & $6.5^{\mathrm{a}}$ & $35.5^{\mathrm{a}}$ & 3 \\
Williams & 0 & $3.5^{\mathrm{b}}$ & $19.5^{\mathrm{b}}$ \\
Body cast & 0 & 1 & 10 \\
Flexion cast & 0 & 2 & 7 \\
Bennett & 0 & 1 & 1 \\
Norton-Brown & 0 & 0 & 2 \\
"Other" braces & 0 & 1 & 2 \\
\hline
\end{tabular}

'Three states showed equal preference for the lumbosacral corset and Chairback brace, thus this value was divided between both columns.

${ }^{b}$ One state showed equal preference for the Chairback and Williams braces as second choice.

those used less frequently (Table 2). The middle and southeastern sections of the United States were the only areas where the Williams brace was used widely; it was fourth in preference on the West coast. With the exception of New York, no mention of it was made in the eastern or New England states. The Bennett brace was second in popularity in Maryland and third in Ohio. Predominance of the Norton-Brown (3) brace was restricted to Massachusetts and Maine, a note consistent with the fact that the originators are from Boston.

\section{CLINICAL INDICATIONS}

The survey form asked the physician to check whether he rarely or usually used some type of support for each of ten clinical conditions listed (Table 3). Three patterns of use were apparent. The responding physicians seldom used external support in the treatment of an acute strain (17\%), for an obese person with pain $(19 \%)$, or during the postoperative period following disc surgery (28\%). When support was used for these conditions, it was generally a corset.

At the other extreme, most physicians used support following spine fusion (84\%), for treatment of spondylolisthesis (70\%), and for pseudoarthrosis $(66 \%)$. In these in- 
Table 3. External Support Preference by Clinical Entrty

\begin{tabular}{|c|c|c|c|c|c|c|}
\hline \multirow[b]{2}{*}{ Clinical Entity } & \multirow[b]{2}{*}{ Total Listing } & \multicolumn{2}{|c|}{ Frequency of Use } & \multicolumn{3}{|c|}{ Support Preference } \\
\hline & & $\begin{array}{c}\text { Rarely } \\
\left(C_{r}\right)\end{array}$ & $\underset{\left({ }^{\circ}\right)}{\text { Usually }}$ & $\begin{array}{c}\text { Brace } \\
\left(c^{\prime}\right)\end{array}$ & $\begin{array}{c}\text { Corset } \\
(\tau)\end{array}$ & $\begin{array}{l}\text { Cast } \\
\text { (c) }\end{array}$ \\
\hline Postoperative fusion & 3590 & 16 & 84 & 51 & 20 & 29 \\
\hline Spondylolisthesis & 3472 & 30 & 70 & 59 & 33 & 28 \\
\hline Pseudoarthrosis & 2784 & 34 & 66 & 57 & 28 & 15 \\
\hline Preoperative trial & 2523 & 46 & 54 & 37 & 25 & 38 \\
\hline Disc syndrome & 3164 & 49 & 51 & 34 & 51 & 15 \\
\hline Chronic backache & 2635 & 52 & 48 & 29 & 67 & 4 \\
\hline Degenerative joint disease & 2818 & 52 & 48 & 32 & 64 & 4 \\
\hline Postoperative disc & 1677 & 72 & 28 & 31 & 65 & 4 \\
\hline Obesity and pain & 1453 & 81 & 19 & 13 & 84 & 2 \\
\hline Acute strain & 1552 & 83 & 17 & 14 & 77 & 9 \\
\hline
\end{tabular}

Tabie 4. Brace Preference by Clinical Entrty, Analysis of 7,142 Responses

\begin{tabular}{|c|c|c|c|c|c|c|c|c|c|c|c|c|c|c|}
\hline \multirow{3}{*}{ Clinical Entity } & \multicolumn{14}{|c|}{ Number and Percentage of Listings } \\
\hline & \multicolumn{2}{|c|}{ Chairback } & \multicolumn{2}{|c|}{ Williams } & \multicolumn{2}{|c|}{ Norton-Brown } & \multicolumn{2}{|c|}{ Goldthwaite } & \multicolumn{2}{|c|}{ Bennett } & \multicolumn{2}{|c|}{ Other } & \multicolumn{2}{|c|}{ Total } \\
\hline & No. & 与 & No. & ; & No. & $\digamma_{F}$ & No. & c & No. & ร & No. & s & No. & $\%$ \\
\hline Postoperative fusion & 845 & 11.9 & 153 & 2.2 & 65 & 0.9 & 45 & 0.6 & 51 & 0.7 & 157 & 2.0 & 1,316 & 18.3 \\
\hline Spondylolisthesis & 856 & 12.0 & 396 & 5.6 & 46 & 0.6 & 56 & 0.8 & 72 & 1.0 & 84 & 1.0 & 1,510 & 21.0 \\
\hline Pseudoarthrosis & 769 & 10.8 & 150 & 2.1 & 49 & 0.7 & 38 & 0.5 & 49 & 0.7 & 98 & 1.4 & 1,153 & 16.2 \\
\hline Preoperative trial & 403 & 5.7 & 141 & 2.0 & 25 & 0.4 & 20 & 0.3 & 37 & 0.5 & 51 & 0.7 & 677 & 9.6 \\
\hline Disc syndrome & 338 & 4.8 & 305 & 4.3 & 29 & 0.4 & 28 & 0.4 & 30 & 0.4 & 52 & 0.7 & 782 & 11.0 \\
\hline \multicolumn{15}{|l|}{ Degenerative joint } \\
\hline disease & 378 & 5.3 & 120 & 1.7 & 15 & 0.2 & 32 & 0.5 & 36 & 0.5 & 76 & 1.0 & 657 & 9.3 \\
\hline Chronic backache & 215 & 3.0 & 120 & 1.7 & 13 & 0.2 & 23 & 0.3 & 19 & 0.3 & 43 & 0.6 & 433 & 6.1 \\
\hline Postoperative disc & 187 & 2.6 & 63 & 0.9 & 20 & 0.3 & 9 & 0.1 & 15 & 0.2 & 39 & 0.4 & 333 & 4.5 \\
\hline Obesity and pain & 45 & 0.6 & 47 & 0.7 & 5 & 0.1 & 10 & 0.1 & 6 & 0.1 & 21 & 0.3 & 134 & 1.9 \\
\hline Acute strain & 62 & 0.9 & 30 & 0.4 & 8 & 0.1 & 6 & 0.1 & 8 & 0.1 & 33 & 0.5 & 147 & 2.1 \\
\hline Total & 4,098 & 57.6 & 1,525 & 21.6 & 275 & 3.9 & 267 & 3.7 & 323 & 4.5 & 654 & 8.7 & 7,142 & 100.0 \\
\hline
\end{tabular}

stances, the most common type of support was a brace.

The orthopedists were evenly divided as to the advisability of prescribing any type of support in treating the degenerative back, the disc syndrome of chronic backache, or as a preoperative trial. A similar lack of agreement was indicated concerning the type of support preferred. As a preoperative trial, there was equal preference for a brace or cast. For the other disabilities, the preferred support was the lumbosacral corset.

Comparison between the specific brace design and the clinical condition (Table 4) showed that the Chairback was the most frequently used brace in each situation, and the Williams brace ranked second in preference. Spondylolisthesis and the disc syndrome were the most common indications for the Williams brace. Spondylolisthesis was also the primary reason for using the Bennett brace. Otherwise, preference for the Norton-Brown, Goldthwaite, and Bennett braces paralleled the use of back support in general.

\section{FUNCTION OF EXTERNAL SUPPORTS}

Three approaches to the data collected on functions of supports seemed pertinent: the general expectation for external supports, the types of support chosen for 
each of these functions, and the functions expected of each of the support designs.

The function most commonly ascribed for external support was restriction of lumbosacral motion (30\%); abdominal support was second (19\%), followed by postural correction $(15 \%)$ and immobilization of the spine $(12 \%)$.

To restrict lumbosacral motion, the Chairback (Knight) brace or a corset were equally preferred. The Williams brace was the third specific device indicated for this purpose, although a larger number of physicians indicated that they used some type of cast to restrict motion.

Abdominal support was most often assigned to the corset. This dominated its next competitor, the Chairback (Knight) brace, by a ratio of two to one. Again, the Williams brace ranked third for the function of supporting abdominal muscles.

Postural correction was almost equally divided between the corset and a Williams brace, although the use of casts was not uncommon.

An interesting situation developed in the category of spinal immobilization. It was the only function identified for the flexion cast, yet this device was fourth in preference. The support most often indicated for spinal immobilization was the Chairback (Knight) brace, a finding which probably reflects its national popularity.

While external supports are seldom used for psychological reasons, when the practice is followed the corset is the most popular device, followed by the Chairback brace.

The concept of unloading the disc has obviously not been accepted by the majority of orthopedic surgeons, since only $8 \%$ indicated this as a function of external support. However, those who did think in these terms showed a strong preference for the Williams brace, with a cast as an alternate.

Focus on the individual types of support showed that the prime functions of the corset were considered to be abdominal support and restriction of lumbosacral motion. The Chairback (Knight) brace was assigned the same functions, but with greater emphasis on restriction of motion. This function was also considered the main purpose of the Williams brace, with correction of posture as its second indication. Casts were generally used to restrict lumbosacral motion, although a surprisingly larger number were also assigned the function of correcting posture. Consistent with the belief that immobilization, as opposed to restriction of lumbosacral motion, is seldom accomplished with external support, even casts were assigned this as a third function.

In addition to completing the survey form, a third of the respondents $(1,034)$ added notes to further explain their preferences. These varied from a single listing of a specific brace to lengthy letters explaining their philosophies of low-back management. A majority of these replies were focused on either the fitting or construction characteristics of their support preferences.

Sixty respondents emphasized the advantages of using exercise early in the treatment of low back pain. Two purposes were expressed: to avoid external support and to overcome the muscle weakening and contracture development that accompanies prolonged immobilization. One respondent summarized this philosophy very succinctly by stating he "never prescribed support without a plan to eliminate it." A smaller group (30) felt that the disadvantages were sufficient to preclude any prescription of external support. All who said they "never" or "rarely" used support emphasized instead their reliance on an organized program of exercise. Specific application of this philosophy was frequently mentioned in relationship to postoperative management of spine fusions. Many respondents also brought out the fact that the treatment of low back pain must be individualized to fit the particular patient's need. This fact must never be forgotten, of course, and the purpose of the survey was not to contradict the concept of individualized patient care, but merely to identify the 
spectrum of external support which physicians have found adequate to meet their multiple goals.

\section{DISCUSSION}

The potential list of 40 external-support designs for low back pain has been severely pruned by the influences of prolonged clinical experience, greater intermingling of orthopedists through professional meetings, and the use of prefabricated parts. Notes by some of the respondents indicated that cost, emphasis on exercise, and early surgery are other important influences.

The clinical indications for use or nonuse of external support were rather sharply defined, but there is no comparable distinction between the accepted styles of support. The latter was indicated by the overlap between clinical entity and support design, as well as by the identification of the functions of the different devices. The mechanical characteristics and the limitations of these various designs which lead to such ambiguity have yet to be objectively identified.

Investigators (3) have found that, unless the support is carefully designed, motion at the lumbosacral joint could be increased with the support rather than restricted. Personal experience indicates that this might also lead to increasing the patient's pain.

A problem still not studied is identification of the characteristics of the patients which govern the choice of support.

\section{SUMMARY}

The lumbosacral corset is the most commonly prescribed external support for low back pain. The Chairback (Knight) and Williams braces are next in preference, with a cast being used least frequently. There is a definite relationship between the etiology of the low back pain and the type of support chosen. The major indication for support prescription is to restrict lumbosacral motion.

\section{REFERENCES}

1. American Academy of Orthopaedic Surgeons, Orthopaedic appliances atlas, vol. 1, braces, splints, shoe alterations, J. W. Edwards, Ann Arbor, Mich., 1952.

2. Nattress, LeRoy Wm., Jr., and Bertram D. Litt, Orthotic services USA 1962, report 2, survey to determine the state of services available to amputees and orthopedically disabled persons, American Orthotic and Prosthetic Assoc, Washington, D.C., 1962.

3. Norton, Paul L., and Thornton Brown, The immobilizing efficiency of back braces: their effect on the posture and motion of the lumbosacral spine, J. Bone Joint Surg., 39A:111-139, January 1957. 


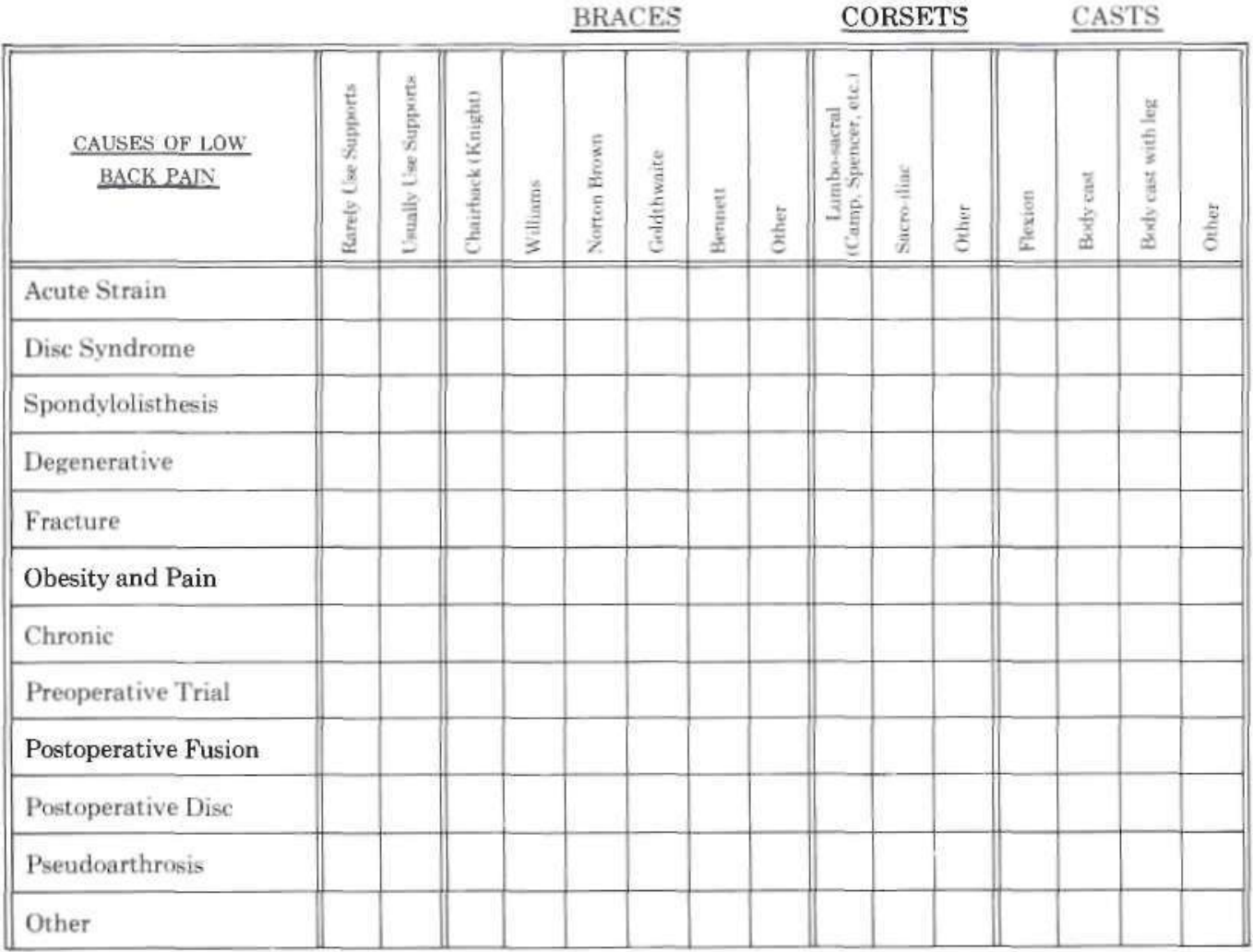

National Survey Phase-Two Questionnaire

CHECK RESULTS YOU EXPECT FROM THE SUPPORTS YOU PRESCRIBE FOR LOW BACK PAIN

\begin{tabular}{|c|c|c|c|c|c|c|c|}
\hline Type of Support & $\begin{array}{c}\text { Immobilizes } \\
\text { spine }\end{array}$ & $\begin{array}{c}\text { Restricts } \\
\text { lumbosecral } \\
\text { motion }\end{array}$ & $\begin{array}{c}\text { Decreases } \\
\text { load on disc }\end{array}$ & $\begin{array}{l}\text { Supports } \\
\text { abdomen }\end{array}$ & $\begin{array}{l}\text { Corrects } \\
\text { posture }\end{array}$ & Psychoiogical & Other \\
\hline \multicolumn{8}{|l|}{$\begin{array}{l}\text { BRACE: } \\
\text { Williams }\end{array}$} \\
\hline \multicolumn{8}{|c|}{ Knight (Chairback) } \\
\hline \multicolumn{8}{|l|}{$\begin{array}{l}\text { Other Braces } \\
\text { (Specify) }\end{array}$} \\
\hline \multicolumn{8}{|l|}{ CORSET } \\
\hline \multicolumn{8}{|l|}{ CAST, flexion } \\
\hline \multicolumn{8}{|c|}{ CAST, other (Specify) } \\
\hline \multicolumn{8}{|l|}{$\begin{array}{l}\text { Other types of } \\
\text { support (Specify) }\end{array}$} \\
\hline & & & & & & & \\
\hline
\end{tabular}

